\title{
LAND-COVER CLASSIFICATION USING FREELY AVAILABLE MULTITEMPORAL SAR DATA (WORK IN PROGRESS)
}

\author{
Mariela Rajngewerc ${ }^{\mathrm{a} *}$, Rafael Grimson ${ }^{\mathrm{a}}$, Juan Lucas Bali ${ }^{\mathrm{b}}$, Priscila Minotti ${ }^{\mathrm{a}}$, Patricia Kandus ${ }^{\mathrm{a}}$ \\ ${ }^{a}$ Instituto de Investigación e Ingeniería Ambiental, Universidad Nacional de San Martín, CONICET, 3iA, Buenos Aires, Argentina - \\ (mraj,rgrimson,pminotti,pkandus)@unsam.edu.ar \\ ${ }^{\mathrm{b}}$ YTEC, YPF-CONICET, Buenos Aires, Argentina \\ juan.lucas.bali@gmail.com
}

KEY WORDS: SAR, Sentinel-1, GLCM, textures, classification, wetlands.

\begin{abstract}
:
Synthetic Aperture Radar (SAR) images are a valuable tool for wetlands monitoring since they are able to detect water below the vegetation. Furthermore, SAR images can be acquired regardless of the weather conditions. The monitoring and study of wetlands have become increasingly important due to the social and ecological benefits they provide and the constant pressures they are subject to. The Sentinel-1 mission from the European Space Agency enables the possibility of having free access to multitemporal SAR data. This study aims to investigate the use of multitemporal Sentinel-1 data for wetlands land-cover classification. To perform this assessment, we acquired 76 Sentinel-1 images from a portion of the Lower Delta of the Paraná River, and considering different seasons, texture measurements, and polarization, 30 datasets were created. For each dataset, a Random Forest classifier was trained. Our experiments show that datasets that included the winter dates achieved kappa index values $(\kappa)$ higher than 0.8 . Including textures measurements showed improvements in the classifications: for the summer datasets, the $\kappa$ increased more than $14 \%$, whereas, for Winter datasets in the $\mathrm{VH}$ and Dual polarization, the improvements were lower than $4 \%$. Our results suggest that for the analyzed land-cover classes, winter is the most informative season. Moreover, for Summer datasets, the textures measurements provide complementary information.
\end{abstract}

\section{INTRODUCTION}

Earth satellite images can provide information about great extension and difficult access natural areas. So, they are an essential tool for mapping wetlands. Furthermore, using satellite images is less expensive than fieldwork-based mapping, and they can provide information in different temporal and spatial scales (Brisco et al., 2011).

The Synthetic Aperture Radars (SAR) signal can penetrate through the vegetation and provide information about flood conditions, underneath vegetation biomass, and soil characteristics (White et al., 2015), depending on the sensor and target characteristics. Thus, SAR satellite images are used for mapping and monitoring wetlands (Hess et al., 2003, Arnesen et al., 2013, LaRocque et al., 2020). Other remarkable points of SAR images are that they provide information about the geometric and dielectric characteristics of the observed target and that they can be acquired regardless of the presence of clouds or lighting conditions.

The Sentinel-1 mission initiated a new age in SAR systems for earth observation. For the first time, multitemporal SAR imagery from all over the world is freely available. Multitemporal SAR data may provide information about the variation of phenological vegetation states and flooding levels in the studied scene. Ozesmi and Bauer (2002) remark the importance of including multitemporal SAR data in wetlands identification.

Although the multitemporal SAR data can provide information about land-covers seasonal characteristics, it does not capture the spatial variation of a pixel's brightness in an image. Landcover classes may show similar backscatter values statistics;

\footnotetext{
* Corresponding author.
}

however, they may have different spectral within-class spectral variability (Oliver and Quegan, 2004). Previous studies (Numbisi et al., 2019, Caballero et al., 2020) show that texture measurements based on the grey level co-occurrence matrix (GLCM) show potential for land-cover classification. These textures describe the spatial relationship of the image pixel values with their spatial distribution in the landscape (Haralick et al., 1973, Hall-Beyer, 2017b).

Remote sensing image classification performance depends on the remote sensing data (selection and manipulation) and also on the classification algorithm (Lu and Weng, 2007). A large variety of classifiers have been explored for land-cover classification using remote sensing data such as Support Vector Machine, Maximum Likelihood, Decision Tree (Otukei and Blaschke, 2010), among others. In the lasts years, Random Forest (RF) became one of the most used supervised algorithms for wetlands mapping (Mohammadimanesh et al., 2018, LaRocque et al., 2020, Mahdianpari et al., 2020) due to the high accuracy of its classifications results, it can handle high data dimensionality and multicollinearity, is fast and insensitive to overfitting (Belgiu and Drăgu, 2016).

In this work, we consider a portion of the Lower Delta of the Paraná River, a wide coastal freshwater wetland located in Buenos Aires, Argentina. Due to the high amount of biomass in all its extent, mapping and monitoring this area is particularly challenging. The main objectives of this work are:

1. to study the potential of multitemporal Sentinel-1 datasets for land-cover maps in densely vegetated areas,

2. to classify the study area and compare the performance of the different multitemporal Sentinel-1 datasets. 
The Sentinel-1 images were processed using the Sentinel's Application Platform (SNAP) (ESA Sentinel Application Platform, 2019). SNAP is an open-source common architecture software for earth observation data manipulation. The Sentinel1 Toolbox (S1TBX) (included in SNAP) consists of a collection of processing tools to pre-process and analyze data from SAR missions such as Sentinel-1, ERS-1 \& 2, ENVISAT, ALOSPALSAR, TerraSAR-X, COSMO-SkyMed, and RADARSAT2.

The classifications were done using Python 3.6 (libraries: sklearn, pandas, numpy, and gdal).

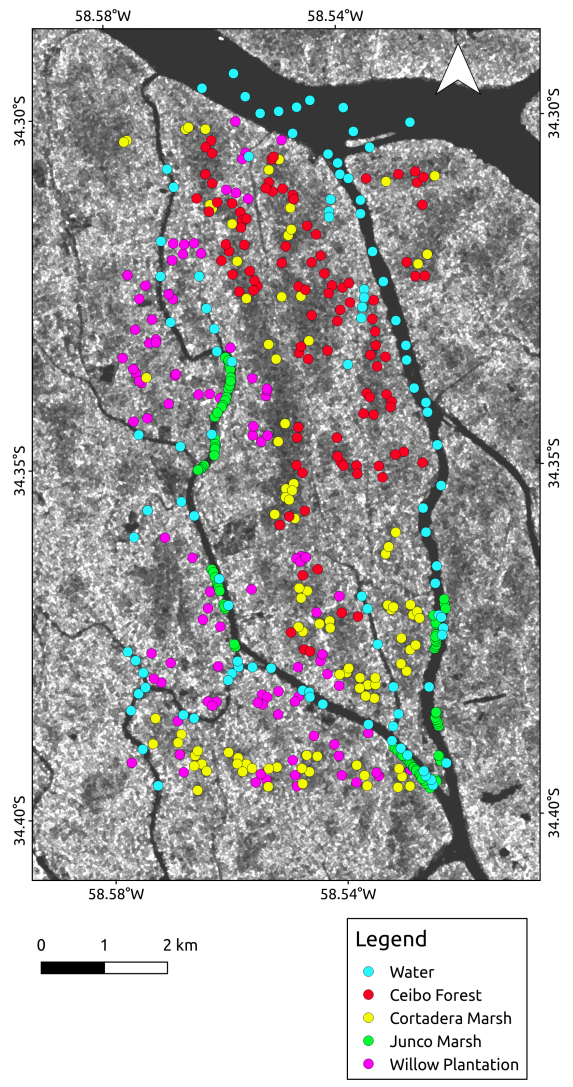

Figure 1. Location of the study area and the reference data for each land-cover class. The background image shows VH band from a Sentinel-1 scene of 1 September 2018.

\section{MATERIALS}

The present work analysis the capability of different datasets to identify the dominant land-cover classes from the Lower Delta of the Paraná River wetland (Argentina) using Sentinel-1 data.

\subsection{Study area}

The study area is located in the Lower Delta of the Paraná River in Buenos Aires, Argentina (Figure 1), encompassing approximately $117 \mathrm{~km}^{2}$ (central coordinates: $34.35^{\circ} \mathrm{S} 58.55^{\circ} \mathrm{W}$ ). Here the climate is humid and temperate, and the annual mean precipitation is approximately $1000 \mathrm{~mm}$.

The studied area is formed by islands. Here, the accumulation of sediments produced by the Paraná distributary rivers forms levees in their borders. Over these natural levees, Willow (Salix spp.) and Poplar (Populus spp.) forest plantation, fruit orchards, and secondary forests are established. Isolated Ceibos with Cortadera marshes (Scirpus giganteus) in the understory or Ceibo forest (Erythrina crista-galli), can be found toward the interior of the islands. In the island's center, where the soil is permanently saturated, Cortadera (S.giganteus) is the dominant species. Junco (Schoenoplectus californicus) beds produce narrow strip marshes at the edge of watercourses (Kandus et al., 2006).

\subsection{Data}

2.2.1 Remote Sensing data Seventy-six Sentinel-1 images from the period October 2016- April 2019 were used in this study. These images were freely downloaded from the Copernicus website (https://scihub.copernicus.eu/dhus/\#/home). The scene product type was Level-1 High-Resolution Ground Rage Detection (GRD) in Interferometric Wide Swath mode; this mode provides VH and VV polarization imagery. All the images were obtained in the descending acquisitions direction with near incidence angles of $29.5^{\circ}$ and far incidence angles of $45.3^{\circ}$.

2.2.2 Reference data For this study, we considered a total of five information classes: one corresponding to the water class and four corresponding to the dominant vegetation classes in the area (Ceibo forest, Willow plantation, Cortadera marsh, Junco marsh).

Experts in local vegetation, using two high-resolution images (Planet Team, 2017) and previous studies in the area (Kandus et al., 2003, Kandus and Malvárez, 2004, Kandus et al., 2006), labeled a total of 496 Regions of Interest (ROIs) (Figure 1). For Water, Ceibo Forest, and Junco Marsh classes sixty ROIs were labeled per class. Fifty-eight ROIS were labeled as Cortadera Marsh and Willow Plantation. With each ROI, a unique pixel was labeled in the Sentinel-1 stacks. This analysis was done using QGIS software (QGIS Development Team, 2016).

\section{METHODS}

In this section, we describe the Sentinel-1 images preprocessing. We explain how we calculated the GLCM-textures for each image and how we created the different datasets. Then, we describe the Random Forest classifier and the accuracy measurements considered in this work.

\subsection{Data pre-processing}

The imagery pre-processing was done using SNAP and Sentinell Toolbox; the pre-processing steps included: thermal noise removal, border noise removal, orbit file application, radiometric calibration, speckle filtering (Refined Lee), terrain flattening, and terrain correction, with the final production of

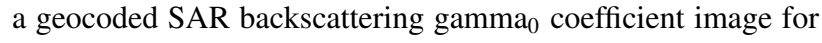
each scene (Filipponi, 2019). Then, we created two stacks, one for each polarization.

\subsection{Extraction of GLCM texture measurements}

Additional features were computed from each gamma 0 stack. Image texture measurements provide information about the relationship between the values of each pixel and its neighboring pixels. The GLCM is one of the most used methods to calculate satellite image texture measurements. The GLCM is a 

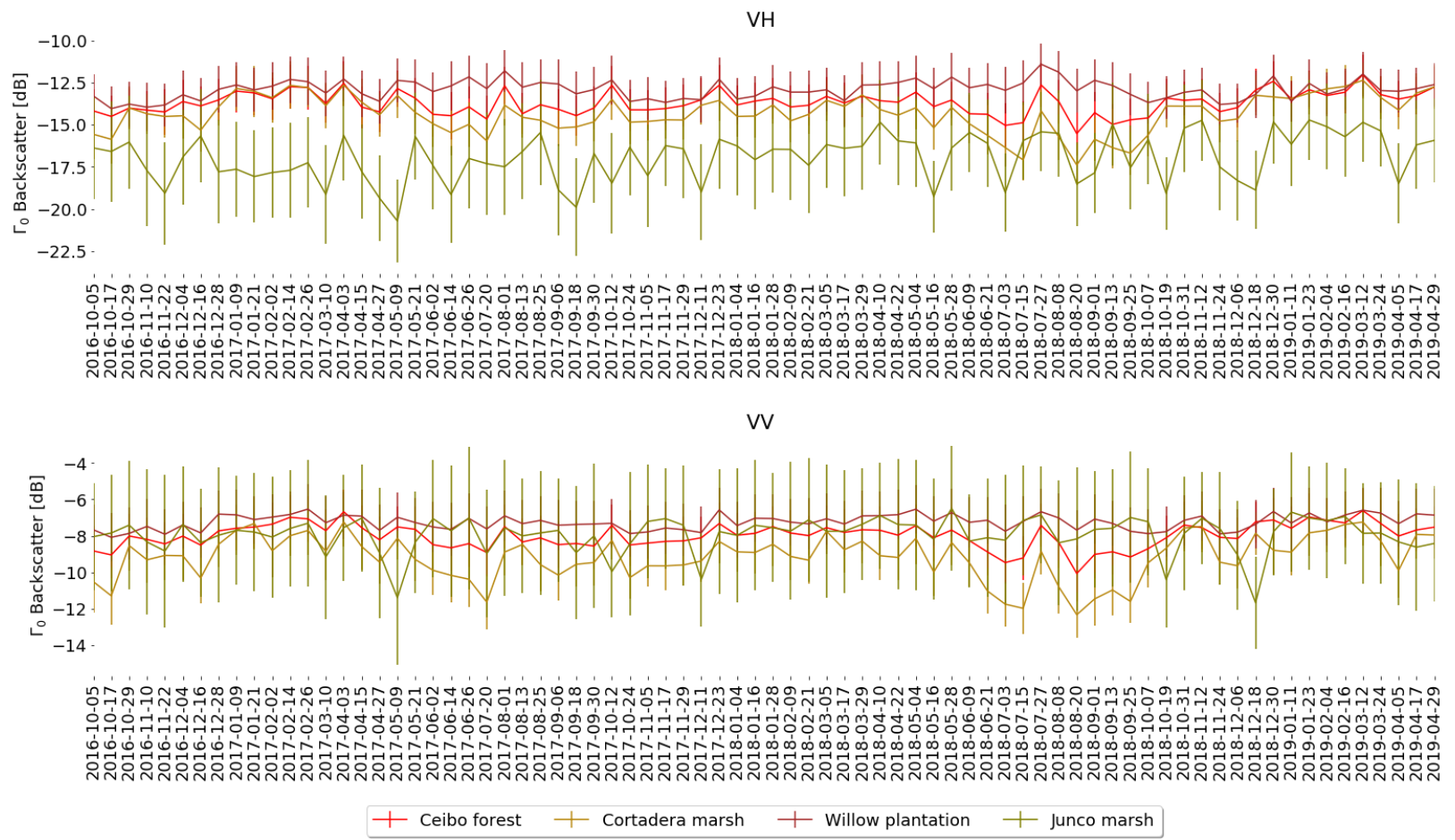

Figure 2. Multitemporal signature of Sentinel-1 gamma values for the reference data vegetation classes of the Lower Delta of the Paraná River. The values are computed as averages of the reference data for each class, and the error bars represent the standard variation of the backscatter value for each date.

tabulation of how often different combinations of pixel intensity values (grey levels) occur in an image (Hall-Beyer, 2017b). Several textures can be calculated based on the GLCM. According to Hall-Beyer (2017), the following texture measures were selected for this study: GLCM-Contrast, GLCM-Correlation, GLCM-Variance, and GLCM-Entropy.

For each processed image, the above-mentioned GLCM textures were calculated using SNAP. For each polarization, a stack containing the four textures was created; the size of each stack is $4 \times 76$.

\subsection{Datasets}

After preprocessing the 76 Sentinel-1 images, we developed thirty multitemporal datasets. In the following, we will say that a dataset is Complete if it is formed by the 76 dates. We will refer as a Winter (Spring/ Summer/Autumn) dataset if it is formed by selecting the winter (spring/summer/autumn) dates from the 76 studied images. Table 1 shows the set of dates associated with each season. We will refer to a Dual dataset if it is composed of the VH and the VV polarizations. Each dataset was created selecting a subset of the 76 dates (Complete, Winter, Spring, Summer, or Autumn), a polarization type (VV,

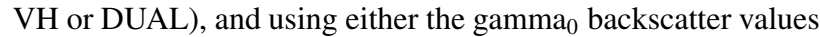
(Intensity) or using the combination of the gamma ${ }_{0}$ with the GLCM textures (Intensity+GLCM).

\subsection{Algorithm and accuracy assessments}

Random Forest (RF) classifier is a widely used algorithm in remote sensing classification tasks (Belgiu and Drăgu, 2016, Mahdianpari et al., 2017). The main objective of this algorithm is to assign a label to a given input (Breiman, 2001). The RF algorithm is formed by multiple decision trees. The user has to select the number of trees to be used. Then, using the training set (i.e., a labeled sampled set), each tree is constructed by selecting a random subset of attributes and is trained using a random subset of the training samples. The main benefit of these random steps is that this way, the algorithm generates different trees. Therefore, we obtain a decrease in the variance of the RF estimator. Once all the trees are trained, the RF classifier can be used to predict an input class. First, the algorithm predicts the input class in each decision tree and then selects the most repeated class as the RF classifier's predicted class.

All datasets were classified using the RF classifier algorithm. The 496 labeled pixels were randomly divided into two sets: training and test sets. The training set is formed by 296 labeled pixels, and the test set is formed by 200 labeled pixels (40 per class).

Once the RF classifier was trained over the training set, the performance was evaluated over the test set. Classification accuracies were assessed using the Overall Accuracy (OA) and Kappa Index Value $(\kappa)$ (Congalton and Green, 2005).

The RF classifier, OA, and $\kappa$ were computed using the implementation provided by the scikit-learn package (Pedregosa et al., 2011) in Python 3.6.

\section{RESULTS}

This section presents the results obtained after applying the RF classifier to each multitemporal dataset. Table 2 shows the $\kappa$ and $\mathrm{OA}$ obtained for each dataset.

\subsection{Temporal analysis}

Figure 2 shows the gamma 0 mean values per date per class. Although the mean values differ, the error bars overlap in all the 


\begin{tabular}{|c|c|c|c|}
\hline Season & Dates & & \\
\hline Spring & $\begin{array}{l}2016-10-05 \\
2016-11-10 \\
2016-12-16 \\
2017-10-24 \\
2017-11-29 \\
2018-10-07 \\
2018-11-12 \\
2018-12-18\end{array}$ & $\begin{array}{l}2016-10-17 \\
2016-11-22 \\
2017-09-30 \\
2017-11-05 \\
2017-12-11 \\
2018-10-19 \\
2018-11-24\end{array}$ & $\begin{array}{l}2016-10-29 \\
2016-12-04 \\
2017-10-12 \\
2017-11-17 \\
2018-09-25 \\
2018-10-31 \\
2018-12-06\end{array}$ \\
\hline Summer & $\begin{array}{l}2016-12-28 \\
2017-02-02 \\
2017-03-10 \\
2018-01-16 \\
2018-02-21 \\
2018-12-30 \\
2019-02-04\end{array}$ & $\begin{array}{l}2017-01-09 \\
2017-02-14 \\
2017-12-23 \\
2018-01-28 \\
2018-03-05 \\
2019-01-11 \\
2019-02-16\end{array}$ & $\begin{array}{l}2017-01-21 \\
2017-02-26 \\
2018-01-04 \\
2018-02-09 \\
2018-03-17 \\
2019-01-23 \\
2019-03-12\end{array}$ \\
\hline Autumn & $\begin{array}{l}2017-04-03 \\
2017-05-09 \\
2017-06-14 \\
2018-04-22 \\
2018-05-28 \\
2019-03-24 \\
2019-04-29\end{array}$ & $\begin{array}{l}2017-04-15 \\
2017-05-21 \\
2018-03-29 \\
2018-05-04 \\
2018-06-09 \\
2019-04-05\end{array}$ & $\begin{array}{l}2017-04-27 \\
2017-06-02 \\
2018-04-10 \\
2018-05-16 \\
2018-06-21 \\
2019-04-17\end{array}$ \\
\hline Winter & $\begin{array}{l}2017-06-26 \\
2017-08-13 \\
2017-09-18 \\
2018-07-27 \\
2018-09-01\end{array}$ & $\begin{array}{l}2017-07-20 \\
2017-08-25 \\
2018-07-03 \\
2018-08-08 \\
2018-09-13\end{array}$ & $\begin{array}{l}2017-08-01 \\
2017-09-06 \\
2018-07-15 \\
2018-08-20\end{array}$ \\
\hline
\end{tabular}

Table 1. Description of the images' dates corresponding to each season.

dates. These overlapping reflect the difficulties to identify the vegetation in the Lower Delta of the Paraná River with Sentinel1 data. During the winter, where the vegetation is in a leaf-off state, the gamma 0 mean values show a subtle difference. One of the objectives of this study is to understand which Sentinel1 dataset leads to a better classification in densely vegetated areas: is the dataset associated with a specific season, or is it the Complete dataset?

For each polarization, the Summer dataset got the lowest performance values, whereas the highest $\kappa$ were obtained using the Winter and the Complete datasets (Table 2). In the case of the Intensity+GLCM-Dual data, $\kappa$ values corresponding to the Winter and Complete dataset differ in less than a $2 \%$. Whereas, in the case of the Intensity-Dual, the Winter and the Complete datasets have the same $\kappa$ value (0.96). In the case of the Intensity-VH and Intensity+GLCM-VH, the Winter and Complete datasets differ in less than $4 \%$.

\subsection{Textural analysis}

The Intensity+GLCM-VH data using the Complete set of dates had the highest $\kappa(0.98)$ and OA (98\%) (Figure 4c). In contrast, the dataset formed by the Intensity data, in the VV polarization and using the Summer dates, achieved the lowest $\kappa(0.69)$ and OA $(75 \%)$.

Incorporating GLCM textures to each Intensity dataset showed an improvement in the $\kappa$ value in all the studied cases. For

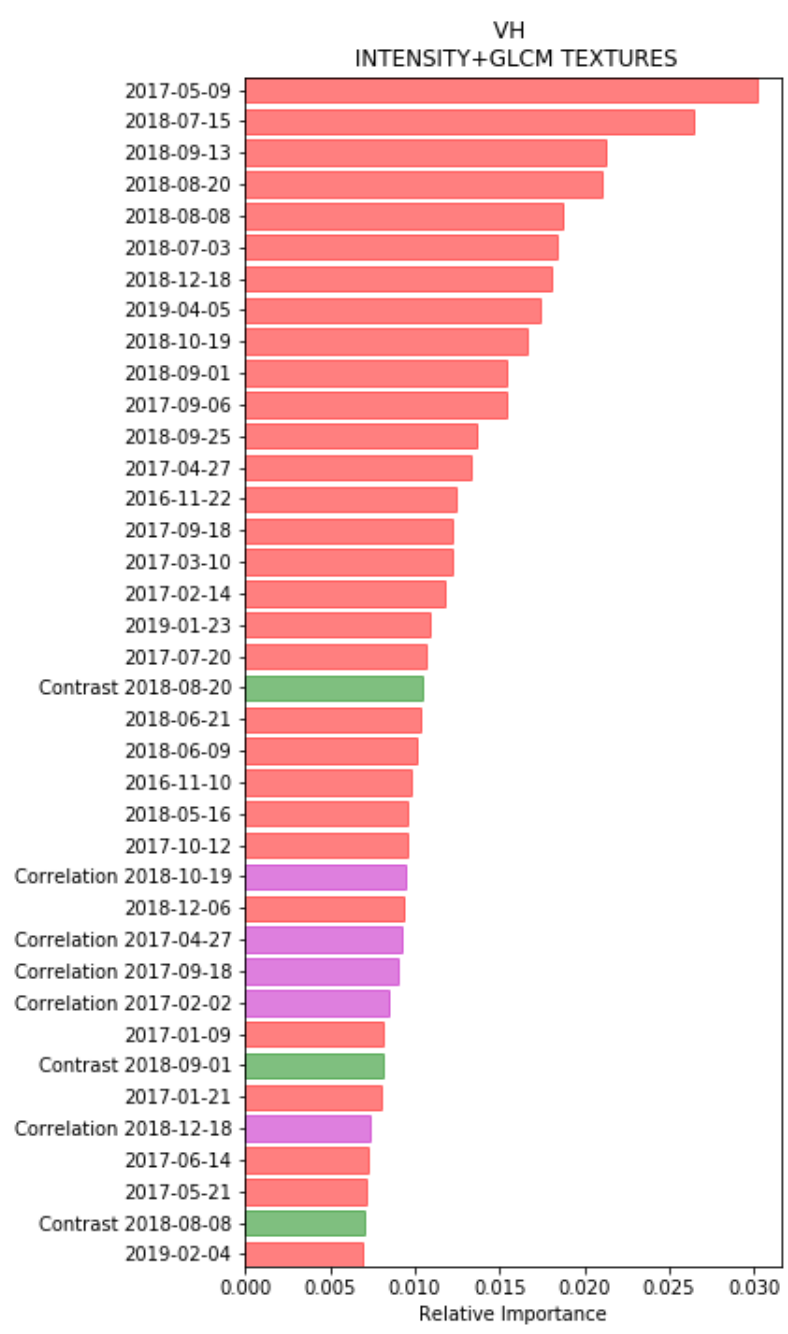

Figure 3. Variable relative importance of Random Forest classification for the dataset formed by the Complete Intensity+GLCM values in the VH polarization. The dataset if formed by 380 variables, the top 38 are presented in the figure.

Different variables are represented as follows: Intensity elements (red), GLCM Contrast texture (green), and GLCM Correlation texture (purple).

Intensity datasets with $\kappa$ values higher than 0.90 , when we incorporated the GLCM textures, the improvement was less than $3.2 \%$. However, for the Intensity datasets with $\kappa$ values lower than 0.8 , the improvement was higher than an $8.25 \%$.

The $\kappa$ values from datasets corresponding to the Dualpolarization and the Intensity data oscillate between 0.75 and 0.94. When we incorporate the texture data to these datasets, i.e., the Intensity+GLCM datasets corresponding to the Dual polarization, the performance values were between 0.89 and 0.96 .

Figure 4 shows the classifications obtained using the Intensity+GLCM datasets from the VH polarization data corresponding to the Summer, Winter, and Complete dates, respectively. Winter and Complete datasets classification show a similar spatial pattern of the land-cover classes. Summer dataset classification shows a much noisier pattern. 


\subsection{Variable importance analysis}

RF classifier enables to estimate the input datasets variable importance, i.e., to score the dataset variables according to its usefulness in predicting the target classes (Breiman, 2001). The classification with the highest $\kappa$ and OA results was the one obtained using the Complete Intensity+GLCM values in the VH polarization dataset. So, this dataset was selected for further analysis. Figure 3 represents the variable importance of the most significant result in this study. The dataset is formed by 380 variables, hence only the top 38 variables are presented in the figure. The five most important variables of this dataset correspond to Intensity VH winter dates. The most important GLCM variable is the GLCM-Contrast texture corresponding to 20 August 2018 and is in the nineteenth place. The sum of all the variables importance is 0.038 for the GLCM-Entropy textures, 0.10 for the GLCM-Variance textures, 0.13 for the GLCM-Contrast textures, and 0.17 for GLCM-Correlation textures.

\begin{tabular}{|c|c|c|c|c|c|}
\hline \multirow{2}{*}{ Polarization } & \multirow{2}{*}{ Dates } & \multicolumn{2}{|c|}{ Intensity } & \multicolumn{2}{|c|}{ Intensity+GLCM } \\
\hline & & $\kappa$ & $\begin{array}{l}\mathrm{OA} \\
(\%)\end{array}$ & $\kappa$ & $\begin{array}{l}\mathrm{OA} \\
(\%)\end{array}$ \\
\hline Dual & $\begin{array}{c}\text { Complete } \\
\text { Autumn } \\
\text { Spring } \\
\text { Summer } \\
\text { Winter }\end{array}$ & $\begin{array}{l}0.94 \\
0.89 \\
0.81 \\
0.75 \\
0.94\end{array}$ & $\begin{array}{l}95 \\
92 \\
85 \\
80 \\
96\end{array}$ & $\begin{array}{l}0.96 \\
0.93 \\
0.93 \\
0.89 \\
0.95\end{array}$ & $\begin{array}{l}97 \\
95 \\
95 \\
92 \\
96\end{array}$ \\
\hline VH & $\begin{array}{c}\text { Complete } \\
\text { Autumn } \\
\text { Spring } \\
\text { Summer } \\
\text { Winter }\end{array}$ & $\begin{array}{l}0.95 \\
0.80 \\
0.76 \\
0.70 \\
0.93\end{array}$ & $\begin{array}{l}96 \\
84 \\
81 \\
76 \\
95\end{array}$ & \begin{tabular}{c|}
$\mathbf{0 . 9 8}$ \\
0.87 \\
0.9 \\
0.84 \\
0.94
\end{tabular} & $\begin{array}{l}\mathbf{9 8} \\
90 \\
92 \\
87 \\
95\end{array}$ \\
\hline VV & $\begin{array}{c}\text { Complete } \\
\text { Autumn } \\
\text { Spring } \\
\text { Summer } \\
\text { Winter }\end{array}$ & $\begin{array}{l}0.86 \\
0.76 \\
0.78 \\
0.69 \\
0.80\end{array}$ & $\begin{array}{l}89 \\
81 \\
83 \\
75 \\
84\end{array}$ & $\begin{array}{l}0.95 \\
0.88 \\
0.88 \\
0.79 \\
0.89\end{array}$ & $\begin{array}{l}96 \\
91 \\
90 \\
84 \\
91\end{array}$ \\
\hline
\end{tabular}

Table 2. Kappa Index Values ( $\kappa$ ) and Overall Accuracy (OA) obtained for Random Forest classifier in different scenarios. Best result indicated in bold.

\section{CONCLUSIONS}

This research aimed to identify the potential of Sentinel-1 data for creating a thematic land-cover map in the Lower Delta of the Paraná River. Based on the 76 dual polarized Sentinel-1 images, and considering different seasons, texture measurements, and polarization, 30 datasets were created. Each dataset was classified using the RF classifier. Then, the classification performances obtained by the different datasets were compared. The experiments indicate that including GLCM-texture measurements and winter dates got higher $\kappa$ and OA performance values.

Whereas this study illustrates the potential of including multitemporal GLCM textures in the datasets, it also raises a question on the contribution of the GLCM-Entropy texture. To better understand the implications of these preliminary results, future studies could address studying the potential of each GLCMtexture in the area and replicating the analysis in other study areas.

\section{ACKNOWLEDGEMENTS}

PlanetScope image courtesy of Planet Labs, Inc. Sentinel-1 data used were available at no-cost from ESA Sentinels Scientific Data Hub.

\section{REFERENCES}

Arnesen, A. S., Silva, T. S. F., Hess, L. L., Novo, E. M. L. M., Rudorff, C. M., Chapman, B. D., McDonald, K. C., 2013. Monitoring flood extent in the lower Amazon River floodplain using ALOS/PALSAR ScanSAR images. Remote Sensing of Environment, 130, 51-61.

Belgiu, M., Drăgu, L., 2016. Random forest in remote sensing: A review of applications and future directions.

Breiman, L. E. O., 2001. Random Forests. Machine Learning, $45,5-32$.

Brisco, B., Kapfer, M., Hirose, T., Tedford, B., Liu, J., 2011. Evaluation of C-band polarization diversity and polarimetry for wetland mapping. Canadian Journal of Remote Sensing.

Caballero, G. R., Platzeck, G., Pezzola, A., Casella, A., Winschel, C., Silva, S. S., Ludueña, E., Pasqualotto, N., Delegido, J., 2020. Assessment of Multi-Date Sentinel-1 Polarizations and GLCM Texture Features Capacity for Onion and Sunflower Classification in an Irrigated Valley: An Object Level Approach. Agronomy, 10(6).

Congalton, R. G., Green, K., 2005. Assessing the accuracy of remotely sensed data principles and practices second edition. Technical report.

ESA Sentinel Application Platform, 2019. SNAP. Version 6, http://step.esa.int.

Filipponi, F., 2019. Sentinel-1 GRD Preprocessing Workflow. Proceedings, 18(1). https://www.mdpi.com/2504$3900 / 18 / 1 / 11$

Hall-Beyer, M., 2017a. GLCM Texture: A Tutorial v. 3.0 March 2017.

Hall-Beyer, M., 2017b. Practical guidelines for choosing GLCM textures to use in landscape classification tasks over a range of moderate spatial scales. International Journal of Remote Sensing, 38(5), 1312-1338.

Haralick, R. M., Shanmugam, K., Dinstein, I., 1973. Textural Features for Image Classification. IEEE Transactions on Systems, Man, and Cybernetics, SMC-3(6), 610-621.

Hess, L. L., Melack, J. M., Novo, E. M. L. M., Barbosa, C. C. F., Gastil, M., 2003. Dual-season mapping of wetland inundation and vegetation for the central Amazon basin. Remote Sensing of Environment, 87(4), 404-428.

Kandus, P., Malvárez, A. I., 2004. Vegetation patterns and change analysis in the lower delta islands of the Paraná River (Argentina). Wetlands, 24(3), 620-632. 

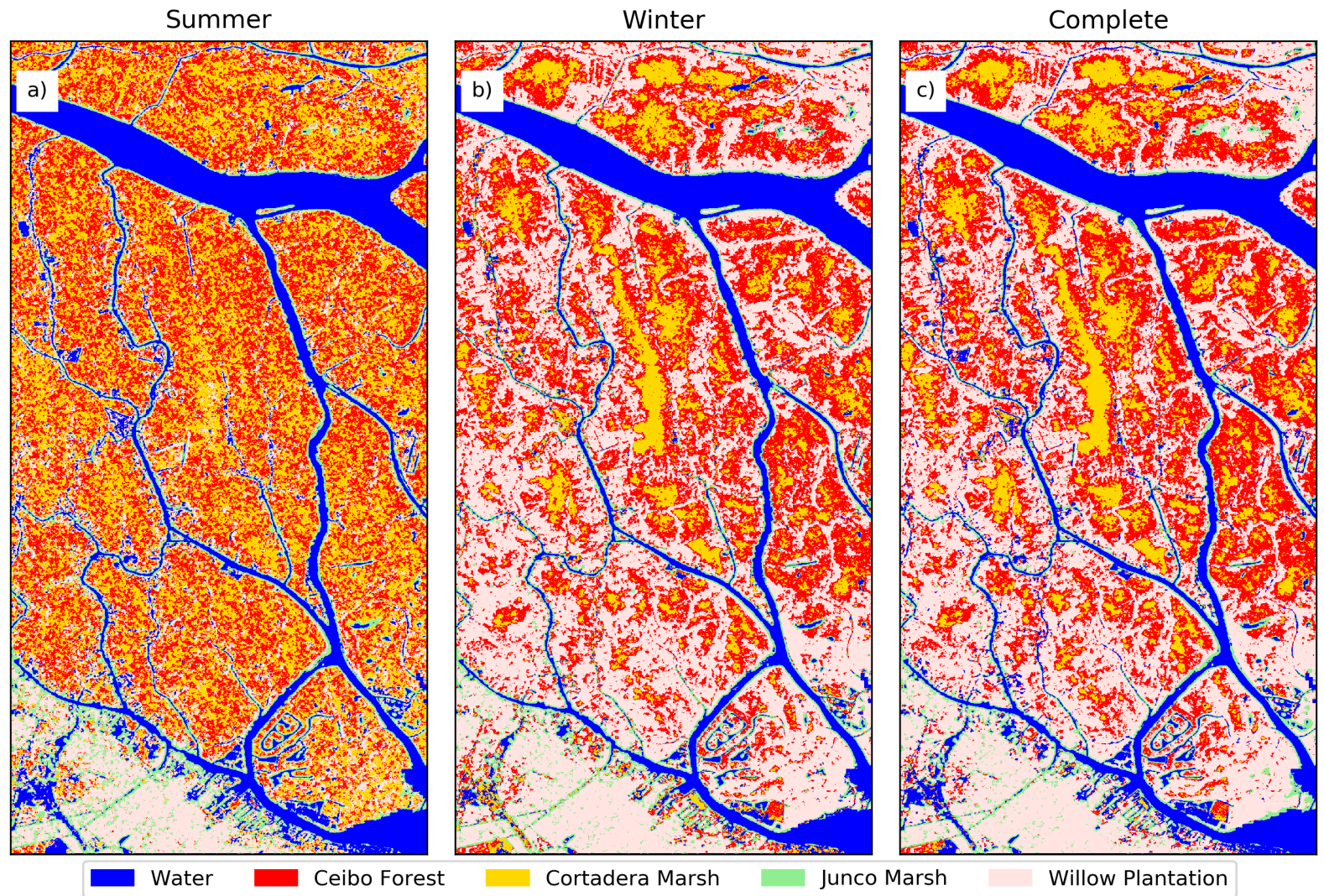

Figure 4. Products of the Random Forest classifications calculated over the: a) Intensity+GLCM-Summer-VH dataset; b) Intensity+GLCM-Winter-VH dataset; c) Intensity+GLCM-Complete-VH dataset.

Kandus, P., Malvárez, A. I., Madanes, N., 2003. Estudio de las comunidades de plantas herbáceas de las islas bonaerenses del Bajo Delta del Río Paraná (Argentina). Darwiniana, 41(1-4), $1-16$.

Kandus, P., Quintana, R. D., Bó, R. F., 2006. Patrones de paisaje y biodiversidad del Bajo Delta del Río Paraná. Mapa de ambientes. Pablo Casamajor, Buenos Aires.

LaRocque, A., Phiri, C., Leblon, B., Pirotti, F., Connor, K., Hanson, A., 2020. Wetland mapping with landsat 8 OLI, Sentinel-1, ALOS-1 PALSAR, and LiDAR data in Southern New Brunswick, Canada. Remote Sensing, 12(13).

Lu, D., Weng, Q., 2007. A survey of image classification methods and techniques for improving classification performance. International Journal of Remote Sensing, 28(5), 823-870.

Mahdianpari, M., Granger, J. E., Mohammadimanesh, F., Salehi, B., Brisco, B., Homayouni, S., Gill, E., Huberty, B., Lang, M., 2020. Meta-analysis of wetland classification using remote sensing: A systematic review of a 40 -year trend in North America.

Mahdianpari, M., Salehi, B., Mohammadimanesh, F., Motagh, M., 2017. Random forest wetland classification using ALOS2 L-band, RADARSAT-2 C-band, and TerraSAR-X imagery. ISPRS Journal of Photogrammetry and Remote Sensing, 130, 13-31.

Mohammadimanesh, F., Salehi, B., Mahdianpari, M., Brisco, B., Motagh, M., 2018. Multi-temporal, multi-frequency, and multi-polarization coherence and SAR backscatter analysis of wetlands. ISPRS Journal of Photogrammetry and Remote Sensing, 142, 78-93.

Numbisi, F. N., Van Coillie, F. M., De Wulf, R., 2019. Delineation of cocoa agroforests using multiseason sentinel-1 SAR images: A low grey level range reduces uncertainties in GLCM texture-based mapping. ISPRS International Journal of GeoInformation, 8(4).

Oliver, C., Quegan, S., 2004. Understanding Synthetic Aperture Radar Images.

Otukei, J. R., Blaschke, T., 2010. Land cover change assessment using decision trees, support vector machines and maximum likelihood classification algorithms. International Journal of Applied Earth Observation and Geoinformation.

Ozesmi, S. L., Bauer, M. E., 2002. Satellite remote sensing of wetlands. Wetlands Ecology and Management, 10, 381-402.

Pedregosa, F., Varoquaux, G., Gramfort, A., Michel, V., Thirion, B., Grisel, O., Blondel, M., Pettenhofer, P., Weiss, R., Dubourg, V., J, V., Passos, A., Cournapeau, D., Brucher, M., Perrot, M., Duchescay, E., 2011. Scikit-learn:Machine Learning in Python. Journal of Machine Learning Research, 12, 2850-2830.

Planet Team, 2017. Planet Application Program Interface: In Space for Life on Earth.

QGIS Development Team, 2016. QGIS Geographic Information System. QGIS Association.

White, L., Brisco, B., Dabboor, M., Schmitt, A., Pratt, A., 2015. A collection of SAR methodologies for monitoring wetlands. 